\title{
Corrections Canada opts for secrecy as it considers call to relinquish authority over health care
}

$\mathrm{F}$ ew cases of prison brutality have attracted more attention than that of Ashley Smith, the 19-year-old who strangled herself in October 2007, while under observation by the Correctional Service of Canada (CSC) staff at the Grand Valley Institution for Women near Kitchener, Ontario.

Eight months after Smith's death, Howard Sapers, Canada's correctional investigator, published A Preventable Death - a scathing report pinpointing 28 causes of her death including num erous violations of federal law and CSC policies.

Sapers called for immediate changes in 16 areas of CSC authority, 15 of which concerned prison management and procedures. The sixteenth urged CSC to consider relinquishing its authority over health care in prisons. "This issue really came to a head for me as we concluded our investigation of Ms. Smith's death," Sapers recalls. "I called for an open discussion of alternatives to CSC running its own health services."

Sapers has continued ever since to question CSC's competence as a health care provider.

In his 2009 report, Sapers urged Ottawa to "look at promising models from other countries" that entrust prison health services to external health care authorities. "We think there is much to learn" from these countries (which include the United Kingdom, France, Norway and much of Australia), Sapers insisted, "and an immediate need to engage the public and initiate the reform process."

CSC commissioned a pair of reports on the issue in 2010 and 2011 from Jim Thomas, a former Ontario deputy labour minister. According to a statement from CSC last year, Thomas' reports “concluded that a contractual or full transfer of CSC health services to other health authorities would be impractical for a number of reasons, primarily stemming

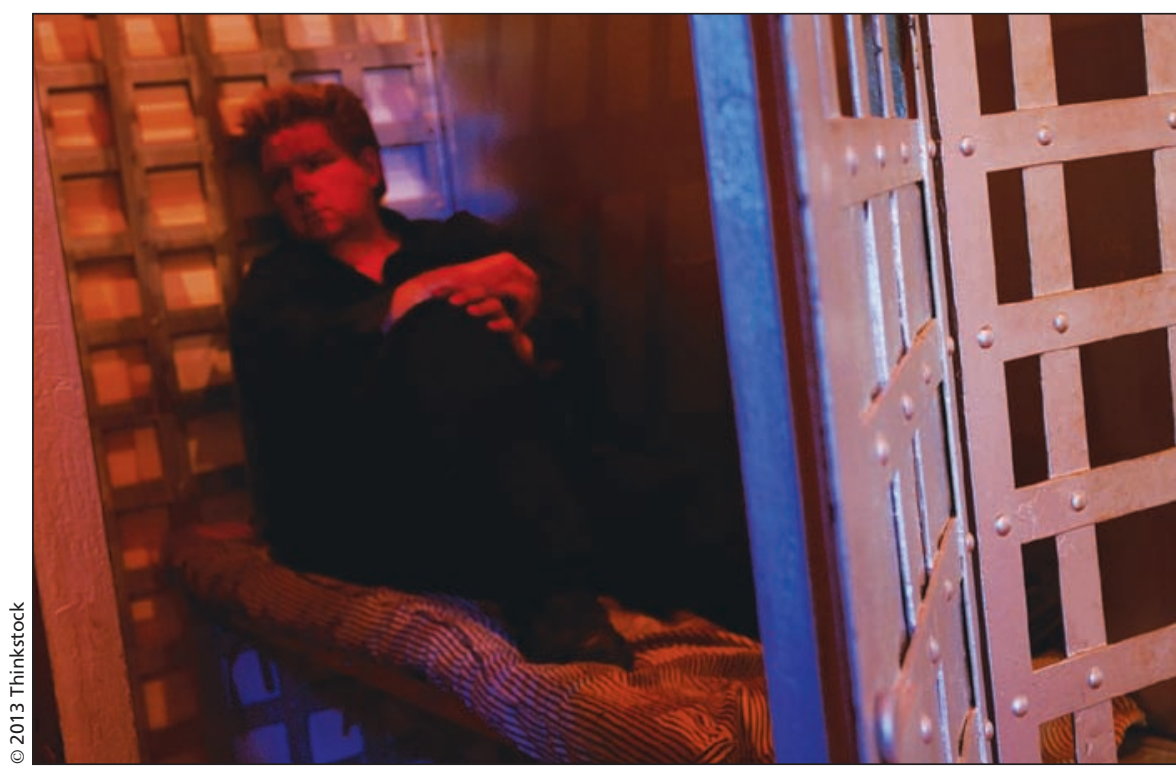

A pair of reports commissioned by the Correctional Service of Canada concluded that transferring or contracting out health services would be impractical.

from the absence in Canada of a national health delivery authority."

And that settled the matter, says the CSC.

Asked for copies of Thomas' reports, CSC spokeswoman Sarah Parkes said they are not publicly available, despite Sapers' calls for a public discussion. And Parkes rejected an interview request to discuss the reports.

The reasons behind the secretiveness become clear after CMAJ obtained copies of the reports through a federal access to information request.

In recommending that the CSC not relinquish control over the health care services it currently operates in 55 institutions, the 24-page report Thomas produced in 2010, which was titled Report on Assessment Framework for Alternative Service Delivery, states that the lack of a national health system is an obstacle. But alongside this, it notes numerous other arguments — based on interviews Thomas conducted with 16 correctional officials, nine public health officials, one academic, a church-based halfway house network and Sapers - against transferring health care out of CSC hands.

Amongst these arguments is the observation that "there often is not a lot of support by the general public for ensuring the health of inmates." Other arguments arrayed by Thomas against Sapers' call for a discussion included worries that contracted health services "might encounter an even greater challenge of being taken seriously" and worries - unsupported by any financial analysis - that it would be too expensive.

Based on these concerns, Thomas recommended the CSC's response to Sapers' request "should not at this point in time include a consideration of the transfer of all services."

So, rather than endorsing Sapers' call for a full and open discussion, Thomas, based on consultations that failed to include a single prisoners' rights advocate, recommended CSC severely restrict any such discussion.

In 2011, Thomas produced a second report on the public discussion that Sapers requested. CMAJ has also 
obtained this report, titled Implementing the CSC Report on Assessment Framework for Alternative Service Delivery, through a request filed under the Access to Information Act. In this report, Thomas again stressed that "the options must not result in the full or contractual transfer of CSC health services to an external health authority."

Noting concerns that "operations officials would lose control over psychologists" and that it would create situations where "correctional professionals report to Health Services," Thomas emphasized that in any discussion of transferring health care programs out of CSC hands, "safety and security are the primary operational objectives and a strong health service environment contributes to those objectives."

But even while asserting that CSC need not even consider relinquishing its health care authority, Thomas noted that many countries, along with the provinces of Alberta and Nova Scotia, have done exactly that. $\mathrm{He}$ also notes that a 2010 World Health Organization paper articulated the rationale for integrating health care in correctional services with public health care on the basis of improved human rights, health care quality, staff recruitment and health care staff independence from correctional authorities.

Remarkably, immediately after rejecting Sapers' suggestion that CSC initiate a public discussion on the issue of transferring health care services into new hands, in his 2010 report, Thomas asserted that his recommendation is in fact "consistent" with Sapers' suggestions that the CSC do precisely that.

Confused? So is Howard Sapers. "We asked CSC to hold a broad consultation discussion about this," he notes, "and they should have a portion of those consultations in public."

In commissioning a pair of reports rejecting a full discussion, and then keeping the reports secret, says Sapers, CSC's response to his calls have been flatly inadequate.

"The very first principle in the [Thomas reports] is that the options must not result in contractual transfer of CSC health services to an external public health authority," he complains. "But I can in fact conceive of a situation where you could transfer everything to an external health authority and make them responsible for everything from immediate and urgent care right through to acute and chronic care."

Sapers says he now wants the CSC to provide a detailed explanation of the barriers to transferring health services from its authority.

"I want them to now tell us what the barriers really are," he insists. "Are they mountains or are they just speed bumps? Just don't tell me it can't be done." Paul Christopher Webster, Toronto, Ont.

CMAJ 2013. DOI:10.1503/cmaj.109-4431 